\title{
Antioxidant Activity of Propofol and Related Monomeric and Dimeric Compounds
}

\author{
Masahiro OGata, ${ }^{*, a, b}$ Kazuo Shin-Ya, ${ }^{c}$ Shiro Urano, ${ }^{b}$ and Toyoshige Endo ${ }^{a}$ \\ ${ }^{a}$ Kyoritsu University of Pharmacy; 1-5-30 Shibakoen, Minato-ku, Tokyo 105-8512, Japan: ${ }^{b}$ Shibaura Institute of \\ Technology; 3-9-14 Shibaura, Minato-ku, Tokyo 108-8548, Japan: and ${ }^{c}$ University of Tokyo; 1-1-1 Yayoi, Bunkyo-ku, \\ Tokyo 113-0032, Japan. Received November 15, 2004; accepted December 23, 2004
}

This study was carried out to investigate the antioxidant activity of propofol (2,6-diisopropylphenol) and its related compounds, butylated hydroxyanisole (BHA), 2,6-dimethylphenol, 2,6-di-t-butylphenol, and their dimeric compounds. The degree of antioxidant activity was evaluated based on the degree of peroxidation induced with Fe-ascorbic acid in egg phosphatidylcholine through the determination of thiobarbituric acid-reactive substances (TBARS) formed during peroxidation. Their antioxidant activities were in the order of dipropofol $>$ di $(2,6-d i-t-$ butylphenol) $>$ diBHA $>$ di(2,6-dimethylphenol). Dipropofol, a dimeric compound of propofol, showed the highest antioxidant activities. Dimeric compounds had higher activities than monomeric compounds, and the 1,1diphenyl-p-picryhydrazyl-trapping ability of dimeric compounds was also greater than those of monomeric compounds (4-10-fold). These results suggest that dimeric phenols may increase their antioxidant activities along with increments in the conjugation system and play a inhibitory role in the propagation of free radical chain reactions.

Key words dipropofol; lipid peroxidation; di(butylated hydroxyanisole); dimeric phenol; free radical; oxidation

In recent years, oxygen-derived free radicals have been reported to be closely involved in many medicobiologic problems such as inflammation, cancer, atherosclerosis, ischemiareperfusion injury, etc. ${ }^{1-5)}$ Free radicals can oxidize biomolecules such as nucleic acid, proteins, lipids, and carbohydrates, which may generate cellular alteration and ultimately lead to tissue injury. Almost all organisms are protected from free radical attack by defense mechanisms. One such mechanism is a preventive antioxidant system that reduces the rate of radical formation, and another is a system to produce chain-breaking antioxidants that scavenge and stabilize free radicals. The free radical production rate may exceed the capacity of the antioxidant defense mechanisms and thereby result in substantial tissue injury. ${ }^{6}$ Recent studies with regard to these aspects have suggested that the antioxidant activities of various agents such as antiallergic drugs, nonsteroidal, antiinflammatory drugs, and traditional Chinese medicines may have clinically some beneficial actions. ${ }^{7-10)}$

Propofol (2,6-diisopropylphenol), a novel sedative and anesthetic agent, is recognized to have potent antioxidant activity. The characteristics of the hindered phenolic structure of propofol, which are similar to those of the tocopherols, butylated hydroxytoluene (BHT), and butylated hydroxyanisole (BHA), might account for the antioxidant activity. ${ }^{11,12)}$ Propofol can reduce ischemia-reperfusion injury after the onset of ischemia. ${ }^{13)}$ In recent research, sulfite from the metabisulfite additive in propofol emulsion was shown to create oxidative environments when the emulsion is exposed to air during a simulated intravenous infusion. This oxidation results in propofol dimerization and propofol dimer quinone formation. ${ }^{14)}$ Their antioxidant activities, however, are still unknown.

In this study, we examined the inhibitory effects of propofol and its related compounds, the dimeric compounds of propofol, 2,6-dimethylphenol and 2,6-di-t-butylphenol, on lipid peroxidation.

\section{Experimental}

Chemicals 2,6-Di-t-butylphenol, 2,6-dimethylphenol, and 2,6-diisopropylphenol (propofol) were purchased from Sigma-Aldrich Japan K.K. (Tokyo, Japan). BHA was purchased from Tokyo Kasei Kogyo Co. (Tokyo, Japan). Egg phoshatidylcholine (PC) was isolated from egg yolk by the previously reported method. ${ }^{15)} \alpha$-Tocopherol was purchased from E. Merck (Darmstadt, Germany). Thiobarbituric acid (TBA), L-ascorbic acid, and $\mathrm{FeSO}_{4}$ were purchased from Tokyo Kasei Kogyo Co., Daichi Kagaku Yakuhin Co., and Kanto Chemical Co. Inc. (all Tokyo, Japan), respectively. 1,1-Diphenyl-2-picrylhydrazyl (DPPH) and ethylenediaminetetraacetic acid disodium salt were purchased from Wako Pure Chemical Co. (Osaka, Japan). $\mathrm{CHCl}_{3}, \mathrm{EtOH}$, pyridine, and $\mathrm{BuOH}$ were purchased from Yoneyama Yakuhin Kogyo Co. (Osaka, Japan). Hydroperoxide was purchased from Mistubishi Gas Kagaku Co. (Tokyo, Japan).

$\mathrm{Fe}^{2+}$ - and Ascorbic Acid-Induced Oxidation of Egg PC and Assessment of Antioxidant Activity Lipid peroxidation was assayed based on thiobarbituric acid-reactive substance (TBARS) formation. ${ }^{16}$ ) Mixtures of a solution of egg PC in chloroform $(200 \mu \mathrm{l} ; 10 \mathrm{mg} / \mathrm{ml})$ and each sample $(100 \mu 1)$ were evaporated to dryness under nitrogen gas. Control and reference substrates with $\alpha$-tocopherol $20 \mu \mathrm{M}$ were also tested for comparison. Lipid peroxidation was initiated by the addition of $\mathrm{FeSO}_{4} 0.2 \mu \mathrm{M}$ and ascorbic acid $2 \mu \mathrm{M}$. After incubation at $37^{\circ} \mathrm{C}$ for $30 \mathrm{~min}$, the reaction was terminated by the addition of EDTA $5 \mu \mathrm{m}$. The oxidation mixture was then mixed with $3 \mathrm{ml}$ of phosphoric acid and $1 \mathrm{ml}$ of aqueous $0.7 \%$ TBA solution and heated at $98^{\circ} \mathrm{C}$ for $45 \mathrm{~min}$. The mixture was extracted with $4 \mathrm{ml}$ of $n$-butanol and the absorbance was measured at $535 \mathrm{~nm}$ with a Hitachi 220A spectrophotometer (Hitachi Seisakusho Co. Ltd., Japan). Antioxidant activity was calculated as follows:

$$
\text { inhibition }(\%)=\frac{A_{\text {control }}-A_{\text {sample }}}{A_{\text {control }}} \times 100
$$

where $A$ represents absorbance.

Synthesis of Dipropofol Propofol $(1 \mathrm{~g})$ was dissolved in $\mathrm{CH}_{2} \mathrm{Cl}_{2}$ and mixed with $\mathrm{CuCl}(\mathrm{OH}) \cdot \mathrm{TMEDA}(16 \mathrm{mg})$ and allowed to stand at room temperature for $5 \mathrm{~h}$. The reaction product was extracted with AcOEt and evaporated. The reactant was dissolved in ethanol, $\mathrm{Na}_{2} \mathrm{~S}_{2} \mathrm{O}_{4}(1 \mathrm{~g})$ was added, and the mixture was heated for $20 \mathrm{~min}$. The precipitate was separated, collected in a filter, and crystallized from hexane to give dipropofol $(950 \mathrm{mg}, 95 \%)$. FAB-MS m/z: $355(\mathrm{M}+\mathrm{H})^{+} .{ }^{1} \mathrm{H}-\mathrm{NMR}\left(500 \mathrm{MHz}, \mathrm{CDCl}_{3}, \delta, \mathrm{ppm}\right): 1.32$ $\left(24 \mathrm{H}, \mathrm{d}, J=6.7 \mathrm{~Hz}, 8 \times \mathrm{CH}_{3}\right), 3.20(4 \mathrm{H}, \mathrm{d}, J=6.7 \mathrm{~Hz}, 4 \times \mathrm{CH}), 7.20(4 \mathrm{H}, \mathrm{s}, \mathrm{H}-$ Ar). HR-FAB-MS: $\mathrm{C}_{24} \mathrm{H}_{35} \mathrm{O}_{2}, 355.2643$; Calcd, 355.2637. mp: $108^{\circ} \mathrm{C}$.

Synthesis of DiBHA BHA $(10 \mathrm{~g})$ was dissolved in pyridine $(10 \mathrm{~g})$ and mixed with $\mathrm{FeSO}_{4}(100 \mathrm{mg})$ and $31 \% \mathrm{H}_{2} \mathrm{O}_{2}(20 \mathrm{~g} \times 3)$ at $60^{\circ} \mathrm{C}$ for $30 \mathrm{~h}$. The reaction product was extracted with AcOEt and distilled by steam distillation. The residue was recrystallized from ethanol to give diBHA $(3.52 \mathrm{~g}$, 
$35 \%)$ as a white solid. FAB-MS $m / z: 359(\mathrm{M}+\mathrm{H})+{ }^{1} \mathrm{H}-\mathrm{NMR}(500 \mathrm{MHz}$, $\mathrm{CDCl}_{3}, \delta$, ppm): $1.43(18 \mathrm{H}, \mathrm{s}, 2 \times t$-butyl $), 3.77\left(6 \mathrm{H}, \mathrm{s}, \mathrm{OCH}_{3}\right), 6.60(2 \mathrm{H}, \mathrm{s}$, $\left.\mathrm{H}-4,4^{\prime}\right), 6.96\left(2 \mathrm{H}, \mathrm{s}, \mathrm{H}-6,6^{\prime}\right) . \mathrm{mp}: 223^{\circ} \mathrm{C}^{17)}$

Synthesis of Di(2,6-di-t-butylphenol) 2,6-Di-t-butylphenol (500 mg) was dissolved in $\mathrm{CH}_{2} \mathrm{Cl}_{2}$ and mixed with $\mathrm{CuCl}(\mathrm{OH}) \cdot$ TMEDA (16 mg) and allowed to stand at room temperature for $2 \mathrm{~h}$. The reaction product was extracted with AcOEt and evaporated. The reactant was dissolved in ethanol, $\mathrm{Na}_{2} \mathrm{~S}_{2} \mathrm{O}_{4}(2 \mathrm{~g})$ was added, and the mixture was heated for $2 \mathrm{~h}$. The precipitate was separated, collected in a filter, and crystallized from hexane to give di(2,6-di- $t$-butylphenol) (481 mg, 96\%). FAB-MS $m / z: 411(\mathrm{M}+\mathrm{H})^{+} .{ }^{1} \mathrm{H}-$ NMR $\left(500 \mathrm{MHz}, \mathrm{CDCl}_{3}, \delta, \mathrm{ppm}\right): 1.47(36 \mathrm{H}, \mathrm{s}, 4 \times t$-butyl), $5.23(2 \mathrm{H}, \mathrm{s}$, $-\mathrm{OH}), 7.36$ (4H, s, H-Ar). mp: $112^{\circ} \mathrm{C} .^{18)}$

Synthesis of $\mathrm{Di}(2,6-d i m e t h y l p h e n o l)$ 2,6-Dimethylphenol (500 mg) was dissolved in $\mathrm{CH}_{2} \mathrm{Cl}_{2}$ and mixed with $\mathrm{CuCl}(\mathrm{OH}) \cdot \mathrm{TMEDA}(16 \mathrm{mg})$ and allowed to stand at room temperature for $5 \mathrm{~h}$. The reaction product was extracted with AcOEt and evaporated. The reactant was dissolved in ethanol, $\mathrm{Na}_{2} \mathrm{~S}_{2} \mathrm{O}_{4}(2 \mathrm{~g})$ was added, and the mixture was heated for $2 \mathrm{~h}$. The precipitate was separated, collected in a filter, and crystallized from hexane to give di(2,6-dimethylphenol) (462 mg, 93\%). FAB-MS m/z: $243(\mathrm{M}+\mathrm{H})^{+} \cdot{ }^{1} \mathrm{H}-$ NMR (500 MHz, $\left.\mathrm{CDCl}_{3}, \delta, \mathrm{ppm}\right): 2.10\left(12 \mathrm{H}, \mathrm{s}, 4 \times \mathrm{CH}_{3}\right), 6.41(2 \mathrm{H}, \mathrm{s}, \mathrm{OH})$, 7.22 (4H, s, H-Ar). mp: $118^{\circ} \mathrm{C} .^{18}$

Trapping Effect of DPPH in Electron Spin Resonance DPPH (2 mM) was dissolved in ethyl alcohol. DPPH spin adducts were measured after exactly $60 \mathrm{~s}$. Electron spin resonance (ESR) spectra were recorded on a JEOLJES-RE1X spectrometer (JEOL Co. Ltd., Tokyo, Japan). The ESR conditions were: power, $0.1 \mathrm{~mW}$; magnetic field, $336.1 \mathrm{mT}$; modulation amplitude, $0.079 \mathrm{mT}$; response time, $0.1 \mathrm{~s}$; receive gain, $\times 500$; sweep time, $0.5 \mathrm{~min}$; and sweep width, $\pm 5 \mathrm{mT}^{19)}$

$\left(\mathrm{H}_{3} \mathrm{C}\right)_{2} \mathrm{HC}$

propofol

(2,6-diisopropylphenol)<smiles>COc1ccc(O)c(C(C)(C)C)c1</smiles>

BHA

\section{Results and Discussion}

One method of evaluating the antioxidant activity of a compound is to assess its free-radical inhibitory activity. An antioxidant should react with free radicals such as the hydroperoxy radical generated from lipid peroxidation and to terminate the propagation of chain reactions. Structures of phenolic compounds are shown in Fig. 1. As shown in Fig. 2 and Table 1, $\mathrm{Fe}^{2+}$-ascorbic acid-induced lipid peroxidation was inhibited significantly in a dose-dependent manner by these compounds. Antioxidant potency decreased in the order: dipropofol $>\operatorname{di}(2,6$-di-t-butylphenol $)>\operatorname{diBHA}>\operatorname{di}(2,6-$ dimethylphenol) $>$ propofol $>2,6$-di- $t$-butylphenol $>$ BHA $>$ 2,6-dimethylphenol. The inhibitory effect of dimerized compounds on lipid peroxidation is greater than that of monomeric compounds.

The DPPH radical, which is very stable, has been employed to determine the free radical-inhibitory effect of some antioxidants. The DPPH radical receives a proton from the antioxidant and becomes a protonated DPPH species. Using this reagent, the free radical-scavenging ability of the antioxidant may be measured using ESR spin-trapping methods. As shown in Table 1, dimeric compounds show strong DPPH radical-scavenging abilities compared with monomeric compounds. The DPPH radical-scavenging ability of monomeric compounds is in the order of propofol $>2$,6-di-t-butylphenol>2,6-dimethylphenol, and for the dimeric com-<smiles>Cc1cccc(C)c1O</smiles>

2,6-dimethylphenol<smiles>CC(C)(C)c1cccc(C(C)(C)C)c1O</smiles>

2,6-di-t-butylphenol

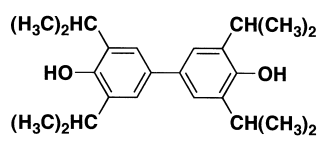

dipropofol

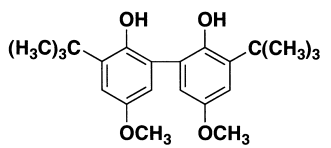

diBHA
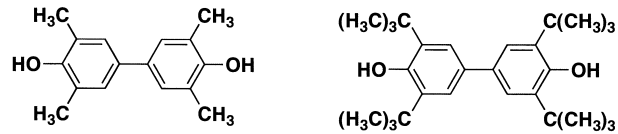

Fig. 1. Structures of Phenolic Compounds Assessed

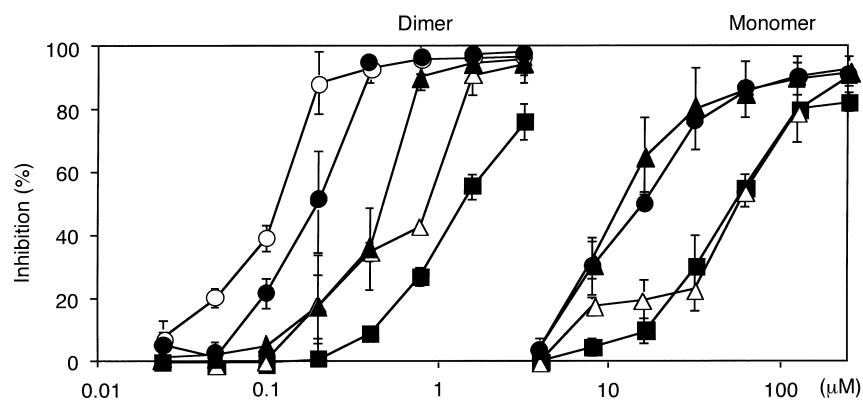

Fig. 2. Inhibition of Lipid Peroxidation by Phenolic Compounds though TBARS Measurement

Dimer: $\bigcirc, \alpha$-tocopherol; $\bullet$, dipropofol; $\triangle$, diBHA; $\boldsymbol{\Delta}$, di(2,6-di-t-butylphenol); di(2,6-dimethylphenol). Monomer: $\bullet$, propofol; $\triangle$, BHA; $\mathbf{\Lambda}$, 2,6-di-t-butylphenol; 2,6-dimethylphenol. Each point and bar represent the mean \pm S.E. $(n=4)$.
Table 1. Inhibition of Lipid Peroxidation and DPPH by Propofol and Related Compounds (Mean \pm S.E., $n=4$ )

\begin{tabular}{lrrr}
\hline \hline \multirow{2}{*}{ Sample } & \multicolumn{2}{c}{ TBA method (\%) } & DPPH \\
& $62.5 \mu \mathrm{M}$ & $250 \mu \mathrm{M}$ & $\mathrm{IC}_{50}(\mu \mathrm{M})$ \\
\cline { 2 - 3 } & $78.2 \pm 3.1$ & $96.0 \pm 0.5$ & $>800$ \\
Propofol & $98.2 \pm 0.1$ & $98.8 \pm 0.1$ & 80 \\
Dipropofol & $74.2 \pm 3.3$ & $95.2 \pm 0.3$ & $>800$ \\
2,6-Di- $t$-butylphenol & $97.3 \pm 0.3$ & $97.6 \pm 0.2$ & 184 \\
Di(2,6-di-t-butylphenol) & $59.0 \pm 1.4$ & $79.6 \pm 0.3$ & $>800$ \\
2,6-Dimethylphenol & $85.1 \pm 0.6$ & $89.0 \pm 0.8$ & 593 \\
Di(2,6-dimethylphenol) & $58.9 \pm 1.8$ & $96.3 \pm 0.2$ & $>800$ \\
BHA & $96.2 \pm 0.4$ & $97.3 \pm 0.1$ & 240 \\
DiBHA & $97.2 \pm 0.1$ & $97.4 \pm 0.1$ & 80 \\
$\alpha$-Tocopherol & & & \\
\hline
\end{tabular}


a

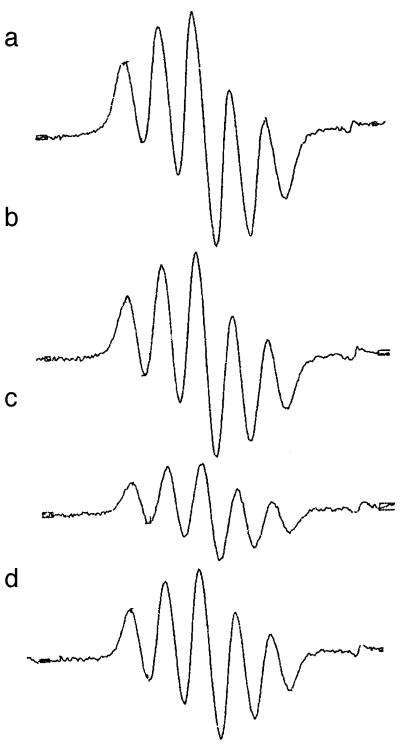

Fig. 3. Trapping Effect of Monomeric Compounds on DPPH Radicals

(a) Control, DPPH (2 mM); (b) DPPH (2 mM)+2,6-dimethylphenol (1.5 mM); (c) DPPH (1.5 mM) + propofol (1.5 mM);(d) DPPH (1.5 mM) +2,6-di-t-butylphenol (1.5 mM).

pounds, the order is dipropofol $>\operatorname{di}(2,6$-di-t-butylphenol $)>$ di(2,6-dimethylphenol) (Table 1, Fig. 3). Interestingly, the order of potency was similar to that of the inhibition of TBARS formation.

To understand the antioxidant mechanism of these phenolic compounds, we analyzed in vitro lipid peroxidation using ESR spectrometry to determine whether they scavenged active oxygen species directly or whether they acted as free radical chain-breaking antioxidants, such as $\alpha$-tocopherol. Relative signal intensities of both the spin adduct DMPO$\mathrm{OOH}$, which is produced by $\mathrm{O}_{2} \cdot{ }^{-}$generated from $\mathrm{HX}-\mathrm{XO}$ systems, and the spin adduct DMPO-OH, produced by hydroxyl radicals through the Fenton reaction, decreased upon the addition of phenolic compounds with antioxidant activity. However, these compounds no decrease in the signal was observed under the experimental conditions used (data not shown).

Several authors have shown that ortho substitution with electron donor alkyl or methoxy groups increases antioxidative action. ${ }^{19-22)}$ Our results also show that ortho substitution with phenolic compounds increased their antioxidative action. The effect of ortho substitution with phenol on activity were in the order; isopropyl $>t$-butyl $>$ methyl (Figs. 2, 3, Table 1).

Drug additives are usually considered inactive formulation components; however, there is evidence that sulfite is responsible for promoting the oxidation of propofol and lipids in emulsions. For example, when propofol emulsions containing metabisulfite (sulfite propofol emulsion) are exposed to air, a propofol dimerized product appears. The antioxidant activity of propofol has previously been demonstrated, but no to the best of our knowledge study has focused on propofol metabolites although propofol undergoes extensive metabolism.

This study was carried out to investigate the antioxidant activity of propofol and its related compounds. Dipropofol exhibited greater antioxidant activity than the other compounds. Our findings suggest that dipropofol may increase its antioxidant effects along with increments in the conjugation system and may increase its inhibitory role in the propagation of free radical chain reactions. Detailed studies on biologic activities are now under way.

Acknowledgments We thank Miss Masae Otomo for helpful assistance. This work was supported in part by a research grant from the Kanpou Science Foundation, Tokyo, Japan; Ministry of Education, Culture, Sports, Science and Technology, Japan; and New Energy and Industrial Technology Development Organization.

\section{References}

1) Reiss U., Gershon D., Biochem. Biophys. Res. Commum., 73, 255262 (1967).

2) Urano S., Hoshi-Hashizume M., Tochigi., Matsui M., Shiraki M., Ito H., Lipids, 26, 58-61 (1976).

3) Sun Y., Free Radic. Biol. Med., 8, 583-599 (1990).

4) Root R. K., Cohen M. S., Rev. Infect. Dis., 3, 565-598 (1981).

5) Henning B., Chow C. K., Free Radic. Biol. Med., 4, 99-106 (1988).

6) Buettner R. G., Arch. Biochem. Biophys., 300, 535-543 (1993).

7) Umeki S., Biochem. Pharmacol., 43, 1109-1117 (1992).

8) Dinis T. S., Maderia V. M., Almeida L. M., Arch. Biochem. Biophys., 315, 161-169 (1994).

9) Shimada O., Yasuda H., Agents and Actions, 19, 208-214 (1986).

10) Ogata M., Hoshi M., Shimotohno K., Urano S., Endo T., JAOCS, 74, 557-562 (1997).

11) Kvam C., Granese D., Flaibani A., Pollesello P., Paolletti S., Biochem. Biophys. Res. Commun., 193, 927-933 (1993).

12) Eriksson O., FEBS Lett., 279, 45-48 (1991).

13) Kato R., Foex P., Can. J. Anesth., 49, 777-791 (2002).

14) Baker T. M., Gregerson S. M., Martin M. S., Buttner R. G., Crit. Care Med., 31, 787-792 (2003).

15) Urano S., Iida M., Otani I., Matsuo M., Biochem. Biophys. Res. Commun., 146, 1413-1418 (1976).

16) Fukuzawa K., Chida H., Sakurai H., Chem. Pharm. Bull., 40, 304 307 (1992).

17) Kurechi T., J. Health Sci., 13, 191-196 (1967).

18) Balogh V., Fetizon M., Golfier M., J. Org. Chem., 36, 1339-1345 (1971).

19) Ogata M., Hoshi M., Urano S., Endo T., Chem. Pharm. Bull., 48, 1467-1469 (2000).

20) Cort W., Food Technol., 10, 60-66 (1974).

21) Chimi H., Sadik A., Tutour L. B., Rahmani M., R. Fr. des Corps Gras, 35, 339-344 (1988).

22) Pokorny J., "Autoxidation of Unsaturated Lipids," ed. by Chan H., Academic Press, London, 1987, pp. 141-206. 